\title{
Verification of the possibility and effectiveness of experiential learning using HMD-based immersive VR technologies
}

\author{
Chongsan Kwon ${ }^{1}$ (D)
}

Received: 11 February 2018 / Accepted: 16 August 2018 / Published online: 28 August 2018

(c) The Author(s) 2018

\begin{abstract}
This paper examines the possibility of experiential learning in a virtual space using head-mounted-display-based immersive virtual reality (VR) technologies. Experiential learning refers to learning through direct experiences in the context of learning. Realistically, experiential learning is impossible in most cases, but VR technologies allowing direct interaction with virtual environments and objects are being developed and commercialized. These technologies are predicted to enhance vividness, interactivity, presence, flow, and experientiality, and increase the expectations of the possibility of experiential learning using VR. Thus, in this study, an experiment was conducted to verify such possibility. The analysis of the experiment results showed that the tactile interactivity and presence improved with the use of enhanced interaction technologies in VR, and in terms of experientiality, the experiment participants became highly aware of the "exploratory stage," referring to the level of experience of being exposed to an interesting site and directly touching an object in the currently enhanced VR in providing direct tactile and locomotive interactivity. Furthermore, the fact that the learning effect is also partially enhanced was discovered. Accordingly, it was determined that experiential learning using VR is possible based on the experiment results, which showed that the enhanced vividness and interactivity of VR technologies allow the users to closely recognize virtual experiences as direct experiences, and that the learning effect is enhanced. It was also determined that experiential learning in a virtual environment that is identical to an experience in reality would be made possible in the near future based on continued technological development.
\end{abstract}

Keywords Virtual reality · Authentic virtual reality $\cdot$ Presence $\cdot$ Experiential learning $\cdot$ Tactile interactivity $\cdot$ Locomotive interactivity

\section{Introduction}

Books have been traditionally used in schools as a learning medium through indirect experiences. The students acquire contents providing indirect experiences and are provided with only symbolized knowledge. To help solve the problem inherent in indirect experiential learning, theories emphasizing direct experience have been formulated, including the experiential learning theory by Dewey $(1959,2004)$ and the

Electronic supplementary material The online version of this article (https://doi.org/10.1007/s10055-018-0364-1) contains supplementary material, which is available to authorized users.

Chongsan Kwon

jazzhana@snu.ac.kr

1 Department of Transdisciplinary Studies, Graduate School of Convergence Science and Technology, Seoul National University, Suwon-si, Gyeonggi-do, Republic of Korea situated learning theory of Lave and Wenger (1991). Dewey (2004) claimed that true and substantial learning is achieved through direct experience although indirect experience is also necessary. Lave and Wenger (1991), on the other hand, emphasized that experience is meaningful in a situational context, and true learning could be achieved through participation in an actual situation. These theories relating to direct experience, however, are difficult to apply to the traditional school curriculum due to spatial, time, and situational contextual restrictions. The universal use of immersive virtual reality (VR) technologies using head-mounted displays (HMDs), which was made possible by the recent development of information and communication technology (ICT) and advanced scientific technologies, will enable learning through a new experiential paradigm.

In the late 1980s and early 1990s, VR technologies were expected to be actively used in various fields, but this did not happen due to their technical restrictions (Bracken and 
Skalski 2010). VR technologies, however, are currently being used in the entertainment sector, such as in games (e.g., https://www.viveport.com/ and https://www.oculu s.com/experiences/gear-vr/), based on the rapid development of vividness and interactivity technologies, which are seen as the core elements needed for an experience in a virtual environment to feel like a real experience. The multidimensional controller (haptic VR controller) providing direct interaction with a virtual environment was particularly designed to provide a natural and realistic experience in a virtual environment (Lang 2016; Robertson 2015). It is predicted that enhanced interaction in a virtual space will make experiential learning resembling reality possible.

This study was conducted to determine whether the experiences acquired through direct interactions with virtual environments and objects, which have become popular of late, could be felt as being closer to direct experiences than the experiences in the existing VR systems providing indirect interactions through gamepads or joysticks. Ultimately, this study intended to determine whether experiential learning is possible through VR.

\section{Literature review}

To determine whether experiential learning is possible through the recognition of virtual experiences as real experiences, the experiential characteristics of VR that will become the measurement and evaluation standard must be examined. Analysis of previous studies revealed that presence and flow are the basic characteristics of VR, and vividness, tactile interactivity, locomotive interactivity, and simulator sickness are the subcomponents contributing to presence.

The most basic characteristic of VR is presence (Barfield and Hendrix 1995; Heeter 1992; Slater and Usoh 1993). Based on many previous studies, the meaning of presence can be compressed into "the sense of being there" (Heeter 1992) and "perceptual illusion of non-mediation" (Lombard and Ditton 1997). Thus, VR experience can be felt as an actual experience. Furthermore, Steuer (1993) proposed vividness and interactivity as the fundamental components contributing to presence, determining the directness of the experience obtained in the virtual environment. Thus, enhanced vividness and interactivity can be considered to strongly influence the direct recognition of VR experience. Here, "vividness" refers to the abundance of reenactment in a mediated environment providing information to the senses, and "interactivity" refers to the level of participation in editing the form and content of the mediated environment in real time (Steuer 1993).

Due to technical restrictions, most of the previous studies in the VR field (e.g., Bracken and Skalski 2010; Heeter
1992; Hou et al. 2012; Neuman 1990; Reeves et al. 1993; Seibert and Shafer 2017; Yuyama 1982; Zeltzer 1992) focused on visual vividness rather than on the vividness of the hearing, touch, smell, and taste perceptions. Studies are currently being conducted, however, on multi-dimensional controllers or data gloves, which allow direct contact with virtual objects. These technologies allowing direct interaction with virtual objects are expected to enhance tactile vividness.

While there have been many studies on vividness, there have been few on the relationship between enhanced interactivity and presence. Despite the increase in the number of video game studies on the effect of the control type on presence (Shafer et al. 2011; Skalski et al. 2011), there has been almost no study on the effect of the controllers in VR environments on the naturalness of the control or presence (Seibert and Shafer 2017). Accordingly, it should be determined whether direct interaction with a virtual object in an HMD-based virtual space could enhance tactile interactivity and presence and directly affect the experience.

Since it is difficult to move in the virtual environment through actual movement, indirect movement using a mouse, keyboard, joystick, or gamepad is used. Accordingly, the locomotive interactivity is deemed limited. Technologies allowing the user to directly walk and move in a virtual space (e.g., https://www.viveport.com/and http://www.virtu ix.com/), however, which are currently being commercialized, can enhance the locomotive interactivity.

In contrast to vividness and interactivity, one component that negatively contributes to presence is simulator sickness (Maraj et al. 2017). Various experimental studies (e.g., Treleaven et al. 2015; Draper et al. 2001) have reported that the use of VR devices applying HMD can cause simulator sickness, which has a negative effect on presence. The analysis revealed that there are study results indicating relief from simulator sickness when the inputs entering the visual and vestibular organs are consistent based on the movement in a virtual space through actual walking and movement (Chance et al. 1998). There are study results indicating, however, that actual walking does not provide relief from simulator sickness (Suma et al. 2007; Zanbaka et al. 2005), and there is a previous study that showed that simulator sickness is not particularly related to presence (Nichols et al. 2000). Thus, it is necessary to re-determine whether actual walking and movement provide relief from simulator sickness, and whether simulator sickness can be deemed to interfere with presence.

Flow refers to the state where a user is so immersed in an activity that he is uninterested in any other activity (Csikszentmihalyi 1990, 2000). Many previous studies have reported that flow positively influences the learning effect (Csikszentmihalyi and Larson 1986; Csikszentmihalyi et al. 1997; Massimini and Carli 1988). Accordingly, the degree of flow 
as a prerequisite of the learning effect must be analyzed. Many previous studies indicated, however, that presence has an effect on flow (Hoffman and Novak 1996; Novak et al. 2000; Zaman et al. 2010); thus, it can be said that flow is an experiential characteristic that can be easily induced in VR.

In general, experiential learning is seen to be achievable through four circulative processes: concrete experience, reflective observation, abstract conceptualization, and active experimentation (Kolb 1984). The step that must precede all the others is direct and concrete experience, which must be placed in a suitable situational context associated with the learning context. Accordingly, to determine whether experiential learning through VR can become true experiential learning, the degree of recognition of an experience in a virtual environment as a direct experience, and the experience steps related thereto, must be ascertained.

Among the scales for measuring the level of experience in experiential learning is the scale of experientiality developed by Gibbons and Hopkins (1980). Experientiality refers to "the degree to which the student's learning experience is between indirect and direct experience, and the depth of the student's involvement in each experience." Gibbons and Hopkins (1980) categorized the forms of learning experience available in schools into the following ten levels: the simulated, spectator, exploratory, analytical, generative, challenge, competence, mastery, personal growth, and social growth stages (Fig. 1). This categorization shares its context and process of enhancing the experientiality of developing indirect experience into direct experience, and direct experience to the direction of a higher dimension (i.e., reflective observation, abstract conceptualization, or active experimentation). In this regard, Priest and Gass (2005) stated that this step of experientiality could be used as an index measuring the degree of practical experience in learning.

In the index of Gibbons and Hopkins (1980) related to the directness of experience, the simulated stage corresponds to the step of indirect experience generally referred to as the experience where "the student passively experiences slides, pictures, videos, and other simulations of reality" (p. 33). The spectator stage corresponds to direct experience focused on vividness, such as directly visiting a site where "the student experiences the object of study with all his senses, but as an observer" (p. 33). The exploratory stage corresponds to an enhanced direct experience focused on vividness and interactivity, much like directly interacting with the surrounding environment by visiting an actual site where "the student is exposed to interesting sites and encouraged to explore the possibilities of the materials at hand" (p. 33). The analytical to the social growth stages are the stages of experience obtained by intensifying learning to enhance the learning experience based on direct experiences in a high dimension. The experiences in these steps are identical to that in the exploratory stage in terms of direct experience, but there is a difference in experientiality based on how the components of the learning content are organized and structured.

The experience of using a medium, such as a book in an existing learning site, corresponds to the experience in the simulated stage, which is generally the lowest level of experientiality. In contrast, when the existing VR is used, the student is provided with an experience like looking at
Fig. 1 Scale of experientiality (Gibbons and Hopkins 1980, p. 36)

\begin{tabular}{|l|l|l}
\hline $\begin{array}{c}\text { Social Growth } \\
\text { Personal Growth }\end{array}$ & Becomes exemplary as a community member \\
\hline Mastery & Pursues excellence and maturity as a person \\
\hline Competence & Strives to become skillful in important activities \\
\hline Challenge & Sets difficult, but desirable tasks to accomplish \\
\hline Generative & Creates, builds, organizes, theorizes, or otherwise produces \\
\hline Analytical & Studies the setting and experience systematically \\
\hline Exploratory & Plays, experiments, explores, and probes the setting \\
\hline Spectator & Sees the real thing in normal setting \\
\hline Stimulated & Sees motives, TV, and slides \\
\hline
\end{tabular}


an actual object as an observer, through vividness-based virtual environment technologies. It can be predicted that experience in the spectator stage is possible. Experience in the exploratory stage is likewise possible through enhanced interactivity in addition to vividness in the VR experience with reinforced interactivity.

\section{Research questions}

To determine whether experiential learning occurs when a virtual experience is recognized as a real experience, experiential learning in a virtual space must be compared to experiential learning in an actual space. It is impossible to realize experiential learning in an actual space, however, with respect to the school curriculum. That is, while one can travel to the past or to outer space in a virtual space, one cannot do so in actual reality. Thus, the experiment itself would be impossible. Accordingly, this study realized experiential learning with VR providing direct interaction and with VR providing indirect interaction, which had been used in the previous experimental studies (e.g., Bailenson et al. 2008; Izard et al. 2017), and conducted a comparative experiment to determine whether the study participants recognized their experience in the recent VR as actual reality compared to their experience in the traditional VR. Furthermore, it was determined that experiential learning would be enhanced by the further development of VR technologies if the study participants recognized their experience in the recent VR as being more like actual reality. Ultimately, it was determined that experiential learning is possible through virtual environments. To conduct such comparison, a relationship between actual reality and VR was set based on the degree of presence, as shown in Fig. 2.

Through movements via actual walking and manipulation of objects via direct contact, VR technology has been rapidly developing in terms of vividness and interactivity.
Compared to simple VR using keyboards or gamepads, this technology can provide an authentic or more realistic experience by providing a stronger presence, and it can be predicted that the user can strongly recognize this authentic virtual experience as a direct experience.

Accordingly, vividness and interactivity are enhanced in a virtual space, such as that shown in Fig. 2, and when presence is reinforced through enhanced vividness and interactivity, it can be assumed that the user can ultimately recognize a virtual experience as an actual experience. Under this assumption, the level of closeness to actuality felt by the user through enhanced vividness, interactivity, and presence was categorized into virtual reality (VR) - authentic virtual reality (AVR) — actual reality. In this regard, AVR is a concept that continuously develops in a direction close to an actual experience, rather than being a fixed concept. The term "authentic" is used in authentic virtual reality (AVR) because the expression "authentic experience" was generally used in previous studies on virtual objects and environments to refer to "an experience that is much like an experience in reality" and "a realistic experience" (Dunleavy 2014; e.g., Izard et al. 2017, Kamarainen et al. 2013; Klopfer and Sheldon 2010, Squire and Jan 2007).

To achieve the objective of this study, the recent VR technology providing direct interactivity was regarded as AVR at the current stage and was compared to the traditional VR providing indirect interactivity. The research questions and hypotheses are shown below.

Research Question 1. Will the experience in AVR be more closely recognized as a direct experience than the experience in VR?

Research Hypothesis 1_1. Presence will be enhanced in AVR compared to VR.

Research Hypothesis 1_2. Vividness will be enhanced in AVR compared to VR.

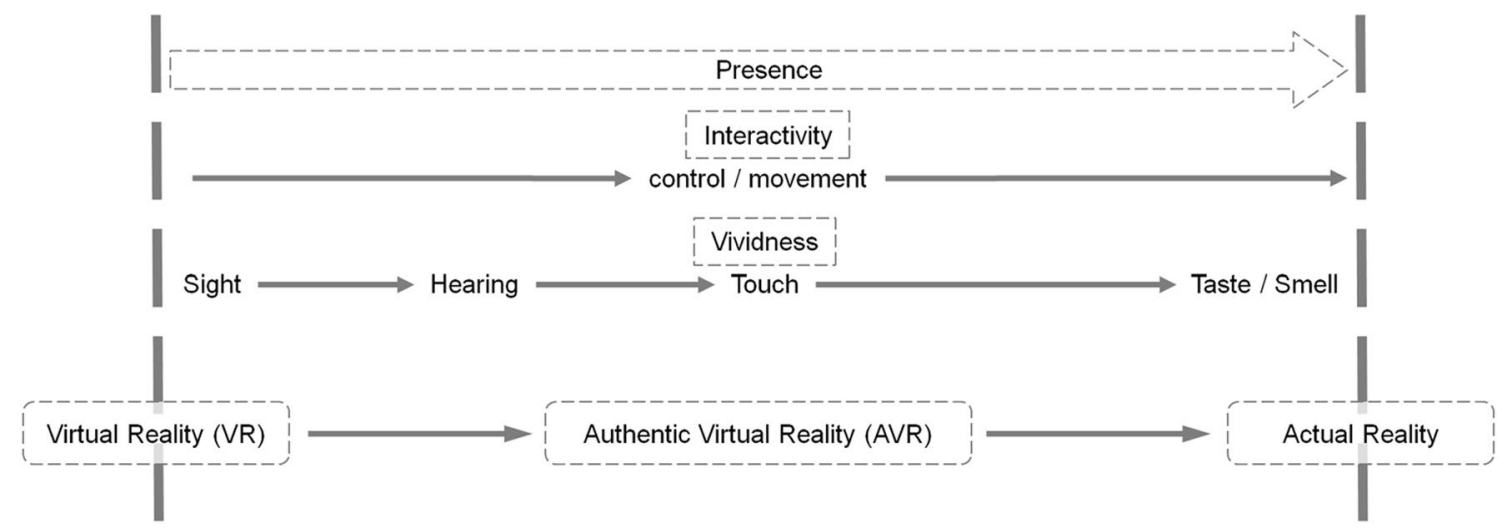

Fig. 2 Relationship between virtual reality and actual reality based on the degree of presence 
Research Hypothesis 1_3. Tactile interactivity will be enhanced in AVR compared to VR.

Research Hypothesis 1_4. Locomotive interactivity will be enhanced in AVR compared to VR.

Research Hypothesis 1_5. Simulator sickness will be relieved in AVR compared to VR.

Research Hypothesis 1_6. Flow will be enhanced in AVR compared to VR.

Based on the analysis of the previous studies' results, it can be considered that virtual experience is recognized more as an actual experience with enhanced presence. Furthermore, the subcomponents that ultimately contribute to presence are vividness and interactivity. Therefore, enhanced vividness and interactivity affect the recognition of the directness of an experience. Simulator sickness has a negative effect on presence, and it can be assumed that presence is enhanced with the alleviation of simulator sickness. Flow is directly affected by presence; therefore, it can be assumed that flow is enhanced in AVR rather than in VR.

Research Question 2. Will the experientiality in AVR be enhanced compared to that in VR?

Research Hypothesis 2_1. Experientiality will be enhanced in AVR compared to VR.

The step of experience can become an important standard in evaluating experiential learning. Although in relation to Research Question 1, however, it can be deemed that experience will be more closely felt as a direct experience in AVR than in VR through the comparison of presence in both, the specific steps of experience cannot be examined. Accordingly, the steps of experience were measured using the steps in the scale of experientiality of Gibbons and Hopkins (1980) deduced in the theoretical analysis.

Research Question 3. Will the learning effect in AVR be enhanced compared to that in VR?

Research Hypothesis 3_1. Academic achievement will be enhanced in AVR compared to VR.

As presence induces flow (Hoffman and Novak 1996; Novak et al. 2000; Zaman et al. 2010) and flow has a positive effect on learning as determined by previous studies (Csikszentmihalyi and Larson 1986; Csikszentmihalyi et al. 1997; Massimini and Carli 1988), it can be assumed that the learning effect will be enhanced by AVR than by VR. Accordingly, the academic achievement based on AVR and that based on VR were comparatively analyzed in this study through the composed academic achievement test sheet.

\section{Experiment}

\subsection{AVR and VR contents}

The "Moon Exploration Learning Game" was developed based on the Earth and Moon unit of a grade 4, second semester elementary school science class. During the content development process, the opinions of the teachers about the contents related to the past and the place that could not be reached would be appropriate for VR learning. In particular, many opined that moon exploration was limited to the plan and could not be implemented through the traditional learning method, and that it would be good to experience the moon's environment and gravity directly in a virtual space. Based on this feedback, the "Earth and Moon" chapter was selected for the experiment in this study. Although it was possible to use the entire curriculum for experiential learning in VR, it was determined that for the purposes of this study, the students should experience contents that were impossible to experience in actual reality. The curriculum had contents comparing the environments of Earth and the moon, and intensive learning allowed the comparative analysis of the gravity on Earth and that on the moon through experience.

AVR and VR suit games as media emphasizing interactivity (Zyda 2005), and the learning contents are presented as a game (Fig. 3). Gaming experience, a clear goal, a set of rules, skill, luck, and reward are generally accepted as game characteristics (Elias et al. 2012; Salen and Zimmerman 2004). Therefore, an adventure game with a story, role, and quest that reflects the general characteristics of games was developed, but unlike the existing computer games, this game provides users with a realistic gaming experience. In the VR game, unlike in the existing computer games, a vivid visual and spatial experience similar to actual reality can be provided through the experience of complete immersion in the game's space. In the case of AVR games, one can break away from the symbolized interaction method of moving and controlling objects using a joystick or a mouse and can have a near-realistic interaction experience by actually walking and touching virtual objects in the game.

Therefore, due to their improved gaming experience characteristics compared to those of the traditional monitor-based computer games, these games are expected to be particularly effective for learning units that are practically impossible to experience, such as the Earth and Moon unit.

To develop the aforementioned game, the instructional process of game-based learning was followed. Prensky (1998) defined game-based learning as a method of learning where the learner attains the learning goal without the teacher's direct involvement, by using an educational 

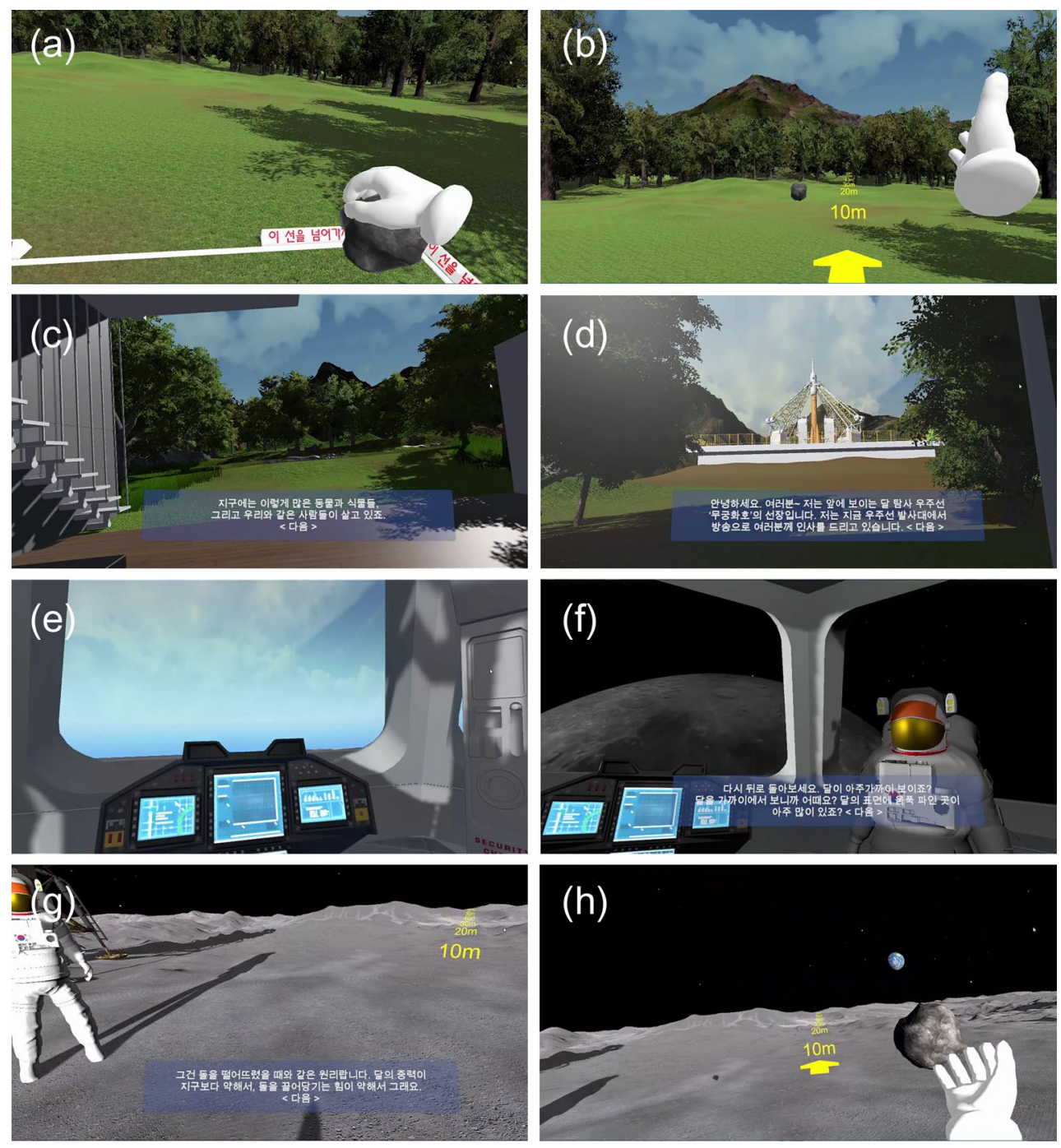

Fig. 3 Game play images of the Moon Exploration Learning Game a, b learning the method of operating the controller and experiencing the gravity on Earth, $\mathbf{c}$ learning about the Earth's environment, $\mathbf{d}$ rocket ship launching station, e launching after boarding the space-

computer game, where the learning contents are incorporated in the game. In game-based learning, which utilizes games as the environment for teaching and learning, most activities (e.g., recognizing learning objectives, acquiring learning contents, and evaluating learning activities) are performed in games. These processes were reflected in the game design. Moreover, the instructor must continuously guide and assist the learners to help them attain the learning goals. In the Moon Exploration Learning Game, the non-player character (NPC), the spaceship captain, plays this role. Game-based learning supports various interactions, induces engagement, and provides the learners with situated learning opportunities (Prensky 1998). These are similar to the goals the authors want to achieve through VR-based learning. Therefore, the use of VR was judged ship, f comparative learning by observing the Earth and moon from outer space, $\mathbf{g}$ learning about the moon's environment after arriving on the moon's surface, and $\mathbf{h}$ experiencing the gravity on the moon

as suitable for creating learning contents according to the instructional process of game-based learning.

Unity 5.4 was used as the game engine, and the programming languages $\mathrm{C \#}$ and Javascript were used. Autodesk Maya 2013 and 3Ds Max 2016 were used for 3D modeling and animation, and the texture and sound were edited using Adobe Photoshop CS2 and Adobe Premiere Pro CS3, respectively. The game was developed through the process shown in Fig. 4. First, the 3D objects that the user can see and interact with in a virtual environment were modeled, and texturing was performed to make the prepared 3D model source appear realistic. The joints were planted and connected to the objects that were required to move, such as virtual hands or animals, and these rigged objects were animated, such as holding a fist and running 


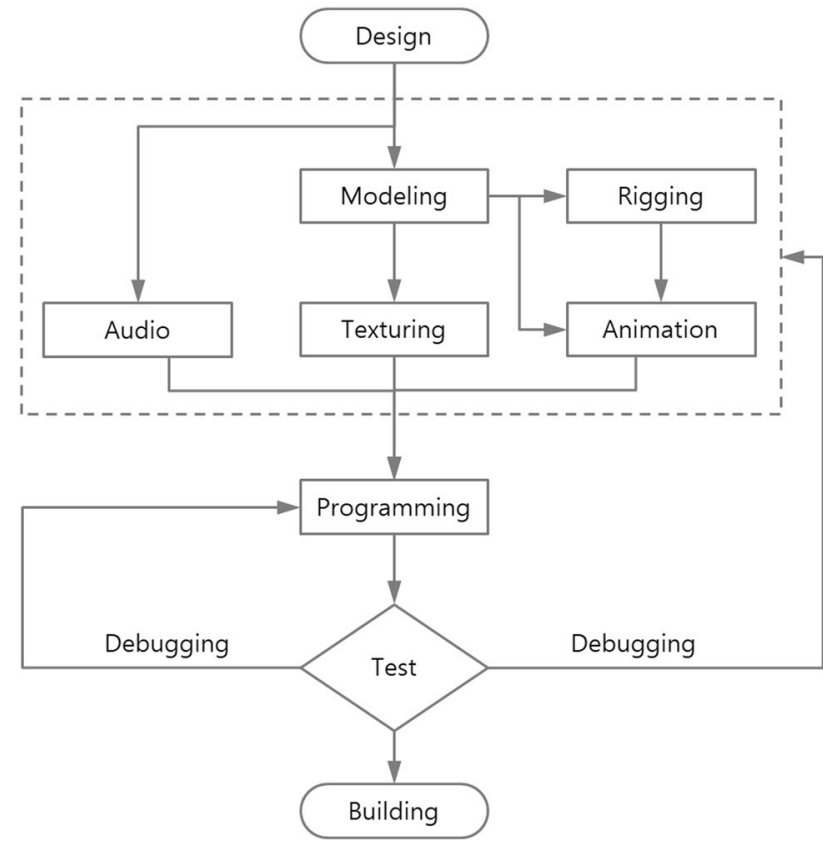

Fig. 4 Game development process

around animals. In addition, audio sources (e.g., rain, wind, and sound of rocket launching) were prepared, and the lines of the spaceship captain were recorded. In the next step, all of these prepared sources were loaded into the game engine and programmed. The game was created after stability verification by a game company specialist, and beta tests were conducted to prevent bug-caused problems.

\subsection{AVR and VR systems}

For the AVR device, this study used HTC's VIVE for the following reasons. First, unlike other AVR devices, VIVE has no age restrictions, thus satisfying the manufacturers' guidelines. Second, VIVE is suitable for conducting research and exploratory activities by moving freely inside a virtual space through wireless-location-tracking-system-type technologies. While treadmill-type AVR devices allow the user to move without restrictions within a certain distance in a virtual space, it is difficult for the user to sit, duck, or jump due to the harness worn on the shoulders or waist for safety reasons, and AVR devices providing a motorized interactivity technology that allows the users to passively move their body through mechanical devices are not suitable for various actions, such as walking, leaning, and picking up virtual objects.

The VR system was used similarly as HMD in VIVE to maintain the same visual and auditory vividness conditions as in AVR, and the user was provided locomotive and tactile interactivity indirectly, through the traditional way of connecting with a PlayStation 4 (PS4) gamepad (Fig. 5).

\subsection{Experiment participants}

The experiment was carried out at small- and medium-sized urban schools in Gyeonggi-do, South Korea, with middleranked national primary school achievement results. As the AVR and VR learning games that were developed for this study had fourth grade semester science curriculum contents, the experiment subjects were grade 4 students (11 years old). A total of 42 students participated in the experiment, 20
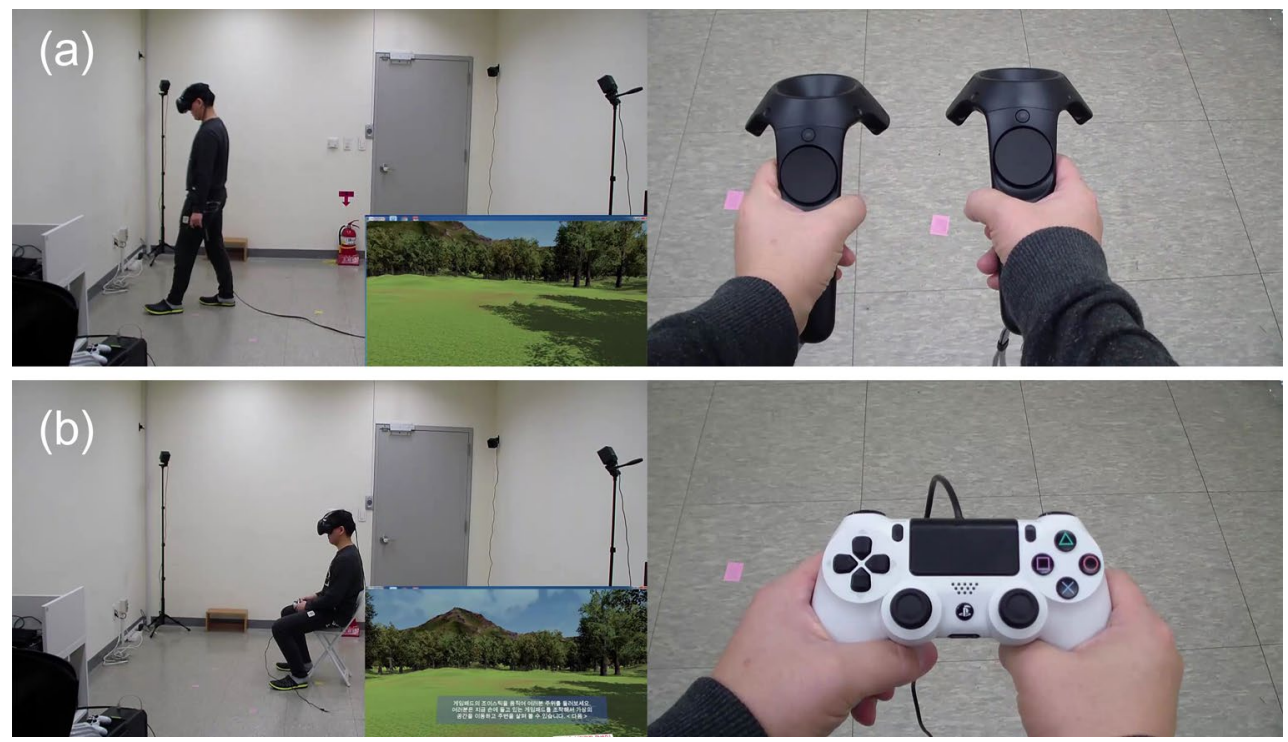

Fig. 5 Images of authentic virtual reality (AVR) and virtual reality (VR) a authentic virtual reality (AVR) and b virtual reality (VR) 
(13 male and 7 female) in the AVR learning game and 22 (12 male and 10 female) in the VR learning game. The participants were selected by the students' homeroom teachers, ensuring an even distribution of students with high and low academic achievement, making both groups homogeneous. All the participants had never used VR before.

\subsection{Procedure}

The experiment was conducted on December 16, 2016, at a school located in Gyeonggi-do, South Korea. All the experiment processes were recorded, and a survey and an achievement evaluation were conducted after the experiment. The experiment was conducted after selecting eight students per class and transferring the students to the experiment site. Four students participated in the AVR learning game, and four in the VR learning game. Two separate rooms were used for the experiment. A counteraction was prepared in case an injury or simulator sickness occurred, after passing the deliberation of the Institutional Review Board (IRB). Each student played the game for 10-15 min and completed the questionnaire and the achievement test for 20-30 min.

To prevent information leakage from the students who had completed the experiment to those who had yet to perform it, all the students who were to participate in the experiment were made to wait in a waiting room, and those who had completed the experiment, survey, and academic achievement test were made to return to their classroom.

\subsection{Measures}

The survey consisted of variables for measuring the recognition of the directness of experience (presence, vividness, tactile interactivity, locomotive interactivity, and simulator sickness), the requisite of the learning effect (flow), and the variable for measuring the learning steps (experientiality). A set of criteria verified in previous studies (Schubert et al. $(1999,2001,2003))$ was used to measure the presence, and another set of criteria verified in other previous studies (Jackson and Marsh 1996) was used to measure the flow. Vividness, tactile interactivity, and locomotive interactivity, which ultimately contribute to presence, were measured using the factors contributing to presence in the study conducted by Witmer and Singer (1998). Witmer and Singer (1998) proposed the control, sensory, distraction, and realism factors as the four elements contributing to presence. Among these, the sensory and realism factors are the criteria related to vividness according to the standards of Steuer (1993), and control is related to interactivity. Accordingly, the vividness questions were deduced from the sensory and realism factors, and the tactile and locomotive interactivity questions were deduced from the control factor. Simulator sickness was measured using the Simulator Sickness
Susceptibility Questionnaire (SSQ) developed by Kennedy et al. (1993).

To measure experientiality, the experientiality criteria developed by Gibbons and Hopkins (1980) were used. The experientiality variable was used to determine the degree of enhancement of the experientiality felt through direct interaction in a virtual space and determines the difference in experientiality between AVR and VR. Accordingly, the experientiality criteria were composed to allow the study participant to select any one among the simulated, spectator, and exploratory stages, which are the steps of direct and indirect experience, by excluding the steps of experience occurring due to the difference in the composition of the contents.

To measure the learning effect, an academic achievement test sheet was developed by educational professionals and teachers in a meeting about the realized game's learning contents, consisting of six questions on the Earth and Moon unit's basic contents and four intensive learning questions on gravity. To determine how well the participants acquired, comprehended, and applied knowledge related to the learned contents, questions were formed to evaluate their remembering, understanding, applying, analyzing, evaluating, and creating processes, which make up Bloom's revised taxonomy of educational objectives (Anderson et al. 2001). The educational professionals and teachers prepared an objective evaluation standard, and they increased its reliability by adjusting the opinions and mutual review of the three evaluators.

As the experiment participants had to measure seven variables including academic achievement, there were restrictions in composing the questions. If there were too many questions, the children with poor concentration could not faithfully respond to the survey, which might affect the result of the examination of their academic achievement. Three questions were prepared for each variable. A 5-point Likert scale was used for the 19 questions, and 10 essay questions were used to measure the academic achievement. SPSS 24 was used to analyze the results. The $t$ test, which can be used for less than 30 samples, was performed for data analysis. In this study, less than 30 samples were obtained, Levene's test for equality of variances was conducted, and the analysis was performed differently based on the assumption of equal variances. The compositions of all the measurement tools are given in Table 1, and the question details are given in Table 2.

\section{Results}

\subsection{Validity of the survey questions}

The subcomponents contributing to presence in AVR and VR (vividness, tactile interactivity, and locomotive 
Table 1 Experiential cognition, experientiality, and academic achievement evaluation tools

\begin{tabular}{llcl}
\hline Item & Variable & $\begin{array}{l}\text { No. of ques- } \\
\text { tions }\end{array}$ & Source \\
\hline Characteristics of VR & Presence & 3 & Schubert et al. (1999, 2001, 2003) \\
& Flow & 3 & Jackson and Marsh (1996) \\
Presence-contributing & Vividness & 3 & Witmer and Singer (1998) \\
components & Tactile interactivity & 3 & Witmer and Singer (1998) \\
& Locomotive interactivity & 3 & Witmer and Singer (1998) \\
& Simulator sickness & 3 & Kennedy et al. (1993) \\
Level of experience & Experientiality & 1 & Gibbons and Hopkins (1980) \\
Learning effect & Academic achievement & 10 & Development of items \\
\hline
\end{tabular}

Table 2 Questions for the experiential cognition and experientiality survey

\begin{tabular}{|c|c|c|c|c|}
\hline Variable & Item & Question & & \\
\hline \multirow[t]{3}{*}{ Vividness } & 1 & $\begin{array}{l}\text { The events that happened in the game created } \\
\text { with the computer felt like real-life events }\end{array}$ & & \\
\hline & 2 & The world in the game felt real to me & & \\
\hline & 3 & I felt like I was on a spaceship & & \\
\hline \multirow[t]{3}{*}{ Tactile interactivity } & 1 & It was easy to grab and throw a rock in the game & & \\
\hline & 2 & $\begin{array}{l}\text { I did not feel uncomfortable when I grabbed and released a } \\
\text { rock on the surface of the moon }\end{array}$ & & \\
\hline & 3 & $\begin{array}{l}\text { I was able to naturally grab and release a rock on the } \\
\text { surface of the moon }\end{array}$ & & \\
\hline \multirow[t]{3}{*}{ Locomotive interactivity } & 1 & $\begin{array}{l}\text { I was able to naturally walk and jump over a long distance } \\
\text { on the surface of the moon }\end{array}$ & & \\
\hline & 2 & $\begin{array}{l}\text { I did not feel uncomfortable at all when walking inside } \\
\text { a spaceship }\end{array}$ & & \\
\hline & 3 & $\begin{array}{l}\text { It was easy to wander around easily while moving in } \\
\text { the game space }\end{array}$ & & \\
\hline \multirow[t]{3}{*}{ Simulator sickness } & 1 & My head hurt. (reverse item) & & \\
\hline & 2 & I felt dizzy. (reverse item) & & \\
\hline & 3 & I felt nauseous. (reverse item) & & \\
\hline \multirow[t]{3}{*}{ Presence } & 1 & $\begin{array}{l}\text { In the computer-generated world, I had a sense of } \\
\text { "being there." }\end{array}$ & & \\
\hline & 2 & I was not aware of my real environment. & & \\
\hline & 3 & I felt like I was just perceiving pictures. (reverse item) & & \\
\hline \multirow[t]{3}{*}{ Flow } & 1 & I felt in total control of what I was doing & & \\
\hline & 2 & I was not concerned with what others might have been thinking of me & & \\
\hline & 3 & Time seemed to alter (either slowed down or speeded up) & & \\
\hline \multirow[t]{3}{*}{ Experientiality } & 1 & Select 1 among the following & & \\
\hline & & It felt like I was watching a movie or TV show. & $\begin{array}{l}\text { It felt like I was looking at an } \\
\text { object in an actual environ- } \\
\text { ment. }\end{array}$ & $\begin{array}{l}\text { It felt like I was walking } \\
\text { in an actual space and } \\
\text { touching real objects. }\end{array}$ \\
\hline & & (Simulated stage) & (Spectator stage) & (Exploratory stage) \\
\hline
\end{tabular}

interactivity) were measured based on measurement criteria according to the theoretical basis, by analyzing previous studies. The validity of the survey questions was verified using exploratory factor analysis. Although the validity of the simulator sickness criterion has been verified, such component affects presence, along with vividness, tactile interactivity, and locomotive interactivity, and is assumed to have a negative relationship with locomotive interactivity. Thus, these components were also analyzed and were found to have been composed based on the relationships between the observed variables and the latent variables proposed in the theoretical analysis, as shown in Table 3. Results showed vividness, tactile interactivity, locomotive interactivity, and simulator sickness criteria satisfy the requirements of the construct validity in the structure of factors. The questions regarding presence and flow have already been verified in various prior studies, and as such, the criteria were directly used in this study. 
Table 3 Results of the exploratory factor analysis of vividness, tactile interactivity, locomotive interactivity, and simulator sickness $(n=42)$

\begin{tabular}{|c|c|c|c|c|c|c|c|}
\hline \multirow[t]{2}{*}{ Factor } & & \multicolumn{6}{|l|}{ Factory analysis } \\
\hline & & Components & Factor loading & Communality & Eigen value & $\begin{array}{l}\text { Explained } \\
\text { variance (\%) }\end{array}$ & $\begin{array}{l}\text { Cumulative } \\
\text { variance (\%) }\end{array}$ \\
\hline \multirow[t]{3}{*}{ Factor 1} & Simulator sickness & Simulator sickness 3 & .876 & .775 & 2.353 & 19.604 & 19.604 \\
\hline & & Simulator sickness 2 & .873 & .801 & & & \\
\hline & & Simulator sickness 1 & .767 & .777 & & & \\
\hline \multirow[t]{3}{*}{ Factor 2} & Vividness & Vividness 3 & .850 & .759 & 2.292 & 19.101 & 38.706 \\
\hline & & Vividness 2 & .818 & .752 & & & \\
\hline & & Vividness 1 & .747 & .703 & & & \\
\hline \multirow[t]{3}{*}{ Factor 3} & Tactile interactivity & Tactile interactivity 2 & .776 & .660 & 2.037 & 16.973 & 55.679 \\
\hline & & Tactile interactivity 3 & .770 & .643 & & & \\
\hline & & Tactile interactivity 1 & .735 & .556 & & & \\
\hline \multirow[t]{3}{*}{ Factor 4} & Locomotive interactivity & Locomotive interactivity 3 & .803 & .754 & 1.861 & 15.506 & 71.185 \\
\hline & & Locomotive interactivity 2 & .756 & .615 & & & \\
\hline & & Locomotive interactivity 1 & .668 & .747 & & & \\
\hline
\end{tabular}

Extraction method: principal component analysis

Rotation method: varimax with Kaiser normalization

$\mathrm{KMO}=0.633$

$P=0.000$

Table 4 Results of the $t$ test analysis for each variable with regard to the experiential characteristics of AVR and VR (one-tailed test)

\begin{tabular}{lllllll}
\hline Variable & Type of learning & $\mathrm{N}$ & $\mathrm{M}$ & $\mathrm{SD}$ & $\mathrm{T}$ & $\mathrm{P}$ \\
\hline Presence & AVR & 20 & 3.70 & 0.94 & 2.28 & $0.01^{*}$ \\
& VR & 22 & 3.03 & 0.96 & & \\
Vividness & AVR & 20 & 4.73 & 0.41 & 1.14 & 0.13 \\
& VR & 22 & 4.55 & 0.62 & & \\
Tactile interactivity & AVR & 20 & 4.82 & 0.28 & 2.78 & $0.00^{* *}$ \\
& VR & 22 & 4.45 & 0.54 & & \\
Locomotive interactivity & AVR & 20 & 4.57 & 0.56 & -0.83 & 0.20 \\
& VR & 22 & 4.70 & 0.45 & & \\
Simulator sickness (reverse item) & AVR & 20 & 1.37 & 0.72 & -2.23 & $0.02^{*}$ \\
& VR & 22 & 1.98 & 1.06 & & \\
Flow & AVR & 20 & 4.13 & 0.66 & -0.94 & 0.18 \\
& VR & 22 & 4.32 & 0.61 & & \\
\hline
\end{tabular}

$* p<0.05, * * p<0.01$

\subsection{Verification of hypothesis}

$<$ Research Question 1 > Will the experience in AVR be more closely recognized as a direct experience than VR experience?

A t test was conducted on each variable for comparative analysis. The analysis showed that the " $t$ " value displayed a positive (+) direction with regard to the presence, vividness, and tactile interactivity factors, while the " $\mathrm{t}$ " value of simulator sickness, which is a reverse item, displayed a negative (-) direction, as shown in Table 4. In addition, statistically significant results were obtained for presence, tactile interactivity, and simulator sickness. Thus, the results complied with the research hypothesis that the survey results of AVR would be higher than those of VR. Although the differences in locomotive interactivity and flow were insignificant, the mean value of VR was high, unlike as hypothesized.

Research Hypothesis 1_1. Presence will be enhanced in AVR compared to VR.

Compared to VR, AVR was significantly enhanced within the 0.05 significance level $(5=2.28, p<0.05)$ (Table 4$)$. Accordingly, it can be said that the AVR learning game participants did not recognize the medium compared to the 
VR learning game participants and had a stronger feeling of being in a virtual space.

Research Hypothesis 1_2. Vividness will be enhanced in AVR compared to VR.

Vividness in AVR was not significantly enhanced compared to vividness in VR $(t=1.14, p>.05)$ (Table 4). This can be attributed to the restrictions of the multi-dimensional controllers that were used in the experiment. With threedimensional controllers, an object is grabbed by pressing a button rather than by sensing through the fingers. It was determined that a restriction occurred in terms of tactile vividness, but the mean value of vividness felt in AVR with the " $t$ " value in a positive $(+)$ direction was higher than that in VR. This can be attributed to the fact that although the subcomponent affecting vividness (visual and auditory vividness) is the same in AVR and VR, the tactile vividness in AVR, which provides direct contact with a virtual object, was enhanced.

Research Hypothesis 1_3. Tactile interactivity will be enhanced in AVR compared to VR.

Tactile interactivity in AVR was significantly enhanced within the 0.01 significance level compared to that in VR $(t=2.78, p<0.01)$ (Table 4). This signifies that the participants who experienced learning through the AVR learning game were able to grab and operate an object in a virtual environment much more easily and naturally than the participants who experienced learning through the VR learning game.

Research Hypothesis 1_4. Locomotive interactivity will be enhanced in AVR compared to VR.

Locomotive interactivity in AVR was not significantly enhanced compared to that in $\operatorname{VR}(t=-0.83, p>0.05)$. The latter showed a higher value, with the " $t$ " value being negative (-) (Table 4). The observation and analysis of the experiment process revealed that this was due to the problems that occurred when the HMD was connected to the system unit using a cable. As can be seen in Fig. 6, it was occasionally observed that when the study participants playing the AVR learning game recognized that the cable was wound around their body as they turned and moved, they stopped and rotated their body in the opposite direction or untangled the wire with their hands to free themselves. The research assistant also had to continually untangle the cable wound around the body of the participant.
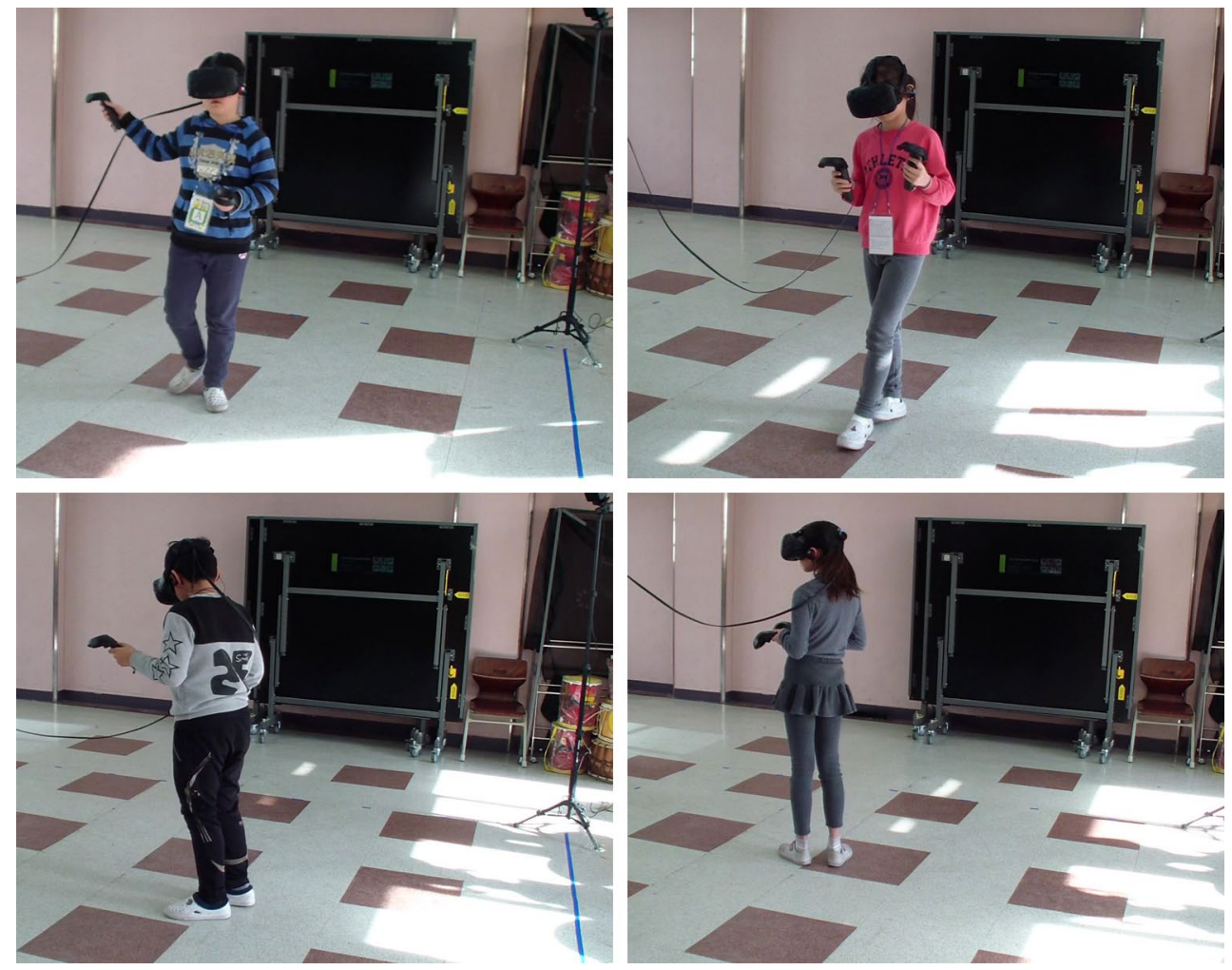

Fig. 6 The cable restricting the movements of the participants 
Research Hypothesis 1_5. Simulator sickness will be relieved in AVR compared to VR.

Simulator sickness in the AVR showed a significant relief within a 0.05 significance level compared to $\operatorname{VR}(t=-2.23$, $p<0.05$ ) (Table 4). This is identical to the results of a previous study (Chance et al. 1998), indicating that direct movement relieved simulator sickness. Although the locomotive interactivity in AVR was not enhanced compared to that in $\mathrm{VR}$, the problem of the simulator sickness in AVR being relieved compared to that in VR was discovered. This may be attributed to the fact that direct walking relived simulator sickness based on the conformity of the visual information with the vestibular organ, as in a previous study (Chance et al. 1998), regardless of the feeling of ease and convenience in movement.

Research Hypothesis 1_6. Flow will be enhanced in AVR compared to VR.

The flow in AVR did not show a significant result compared to that in VR $(t=-0.94, p>0.05)$ (Table 4), and the " $t$ " value showed a negative (-) direction. It was found that the VR learning game participants showed a higher mean

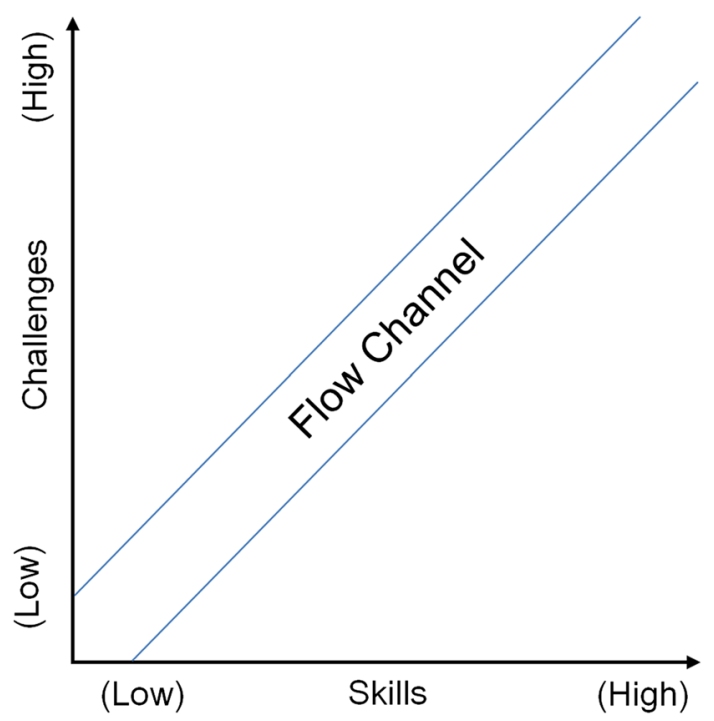

Fig. 7 Balance of skills and challenges (Csikszentmihalyi 1990, p. 74)

Table $5 T$ test analysis results on experientiality of AVR and VR (one-tailed test) value, contrary to the hypothesis. This result can be interpreted from two perspectives.

First, the flow theory must be examined. In the said theory (Chikszentimihayi 1990), when a challenge task and a personal technique or skill that can resolve it maintain a reasonable tension (when the challenge task maintains a certain level of difficulty), flow occurs (Fig. 7). The learning game contents developed for the experiment, however, had excessively easy challenge tasks in terms of AVR, such as picking up and throwing a stone, walking, or jumping, because it is within the framework of the regular curriculum. It was determined that picking up and throwing a stone with the hand using a three-dimensional controller, walking, and jumping were too easy to induce a strong flow in the AVR learning game participants.

Second, the cable that connected the HMD to the system unit, which had a negative effect on locomotive interactivity, not only induced the AVR participants' feeling that they could not freely move but also weakened the flow through the cognition of the actual space outside the game. The cable weakened the participants' sense of control while playing the game by continually twisting around their body, and it appeared that the participants recognized the external situation while receiving help from the research assistant or personally unwinding the cable from their body.

$<$ Research Question 2 > Will experientiality in AVR be enhanced compared to that in VR?

Research Hypothesis 2_1. Experientiality will be enhanced in AVR compared to VR.

The analysis of the $t$ test results revealed that experientiality in AVR was significantly enhanced within a significance level lower than 0.01 compared to that in $\operatorname{VR}(t=2.34, p<0.01)$ (Table 5), which conformed with the research hypothesis. Accordingly, the AVR learning game participants felt stronger experientiality of actually touching and operating an object in a virtual space compared to the VR learning game participants. Specifically, the frequency analysis of the survey question responses revealed that most (17) of the AVR learning game participants selected the responses pertaining to the exploratory stage, whereas only 9 of the students who participated in the VR learning game selected the responses pertaining to the simulated and spectator stages (Table 6). Thus, almost half of the student participants selected a relatively low experience compared to that in AVR. Accordingly, in terms of the steps of

\begin{tabular}{lllllll}
\hline Questions & Type of learning & $\mathrm{N}$ & $\mathrm{M}$ & $\mathrm{SD}$ & $\mathrm{T}$ & $\mathrm{P}$ \\
\hline Experientiality & AVR & 20 & 4.70 & 0.73 & 2.34 & $0.01^{* *}$ \\
& VR & 22 & 3.82 & 1.59 & & \\
\hline
\end{tabular}

$* * p<0.01$ 
Table 6 Results of the frequency analysis of the AVR and VR experiment participants' selection of the experientiality stage

\begin{tabular}{llll}
\hline Type $(\mathrm{N})$ & Simulated stage & Spectator stage & Exploratory stage \\
\hline AVR (20) & $0(0 \%)$ & $3(15.0 \%)$ & $17(85.0 \%)$ \\
VR (22) & $4(18.2 \%)$ & $5(22.7 \%)$ & $13(59.1 \%)$ \\
\hline
\end{tabular}

experientiality according to Gibbons and Hopkins (1980), the experience in AVR is closer to that in the exploratory stage of directly touching an object and being exposed to an interesting site, whereas an experience in VR is closer to the spectator stage of looking at an actual object. Thus, there is a difference in the degree of experientiality between AVR and VR.

$<$ Research Question $3>$ Will the learning effect in AVR be enhanced compared to that in VR?

Research Hypothesis 3_1. Academic achievement will be enhanced in AVR compared to VR.

The comparative analysis through a test on the academic achievement scores of the group that used the AVR learning game and the group that used the VR learning game displayed significant results for question 8 , which requires a complex level of thinking, as shown in Table $7(t=2.39, p<.05)$.

The academic achievement questions were categorized into Bloom's revised taxonomy of educational objectives (Anderson et al. 2001), which are based on the degree of complexity of the required thinking processes (remembering, understanding, applying, analyzing, evaluating, and creating), and were distributed according to their total difficulty level. First, so that the survey would not be too difficult, six remembering questions (with the lowest complexity level; questions 1-1, 1-2, 3, 5-1, 5-2, and 7) were formulated. These questions evaluated the participants' skill in remembering the learned contents, such as facts or rules. Next, to evaluate if the participant properly understood the learned contents, one question on comprehension was formulated (question 2), and to evaluate the skill of applying the learned contents to new situations, two questions on application were formulated (questions 4 and 6). Lastly, to determine whether the participants recognized the difference by comparatively analyzing the learned contents, and to apprehend the entire relation and draw creative ideas, one question on analysis, evaluation, and creation was formulated (question 8).

Table 7 Results of the analysis of the $t$ test results on academic achievement of AVR and VR (one-tailed test)

\begin{tabular}{|c|c|c|c|c|c|c|c|c|}
\hline Question & Taxonomy of educational objectives & Learning method & Learning type & $\mathrm{N}$ & M & SD & $\mathrm{T}$ & $\mathrm{P}$ \\
\hline \multirow[t]{2}{*}{$1-1$} & \multirow[t]{2}{*}{ Remembering } & \multirow[t]{2}{*}{ Visual and auditory vividness } & AVR & 20 & 3.00 & 0.00 & \multirow[t]{2}{*}{1} & \multirow[t]{2}{*}{0.16} \\
\hline & & & VR & 22 & 2.86 & 0.64 & & \\
\hline \multirow[t]{2}{*}{$1-2$} & \multirow[t]{2}{*}{ Remembering } & \multirow[t]{2}{*}{ Visual and auditory vividness } & AVR & 20 & 2.50 & 2.57 & \multirow[t]{2}{*}{0} & \multirow[t]{2}{*}{0.5} \\
\hline & & & VR & 22 & 2.50 & 2.56 & & \\
\hline \multirow[t]{2}{*}{2} & \multirow[t]{2}{*}{ Understanding } & \multirow[t]{2}{*}{ Interactivity } & AVR & 20 & 5.00 & $0.00^{\mathrm{a}}$ & \multirow[t]{2}{*}{-} & \multirow[t]{2}{*}{-} \\
\hline & & & VR & 22 & 5.00 & $0.00^{\mathrm{a}}$ & & \\
\hline \multirow[t]{2}{*}{3} & \multirow[t]{2}{*}{ Remembering } & \multirow[t]{2}{*}{ Visual and auditory vividness } & AVR & 20 & 4.60 & 0.82 & \multirow[t]{2}{*}{0.44} & \multirow[t]{2}{*}{0.33} \\
\hline & & & VR & 22 & 4.45 & 1.26 & & \\
\hline \multirow[t]{2}{*}{4} & \multirow[t]{2}{*}{ Applying } & \multirow[t]{2}{*}{ Interactivity } & AVR & 20 & 5.00 & $0.00^{\mathrm{a}}$ & \multirow[t]{2}{*}{-} & \multirow[t]{2}{*}{-} \\
\hline & & & VR & 22 & 5.00 & $0.00^{\mathrm{a}}$ & & \\
\hline \multirow[t]{2}{*}{$5-1$} & \multirow[t]{2}{*}{ Remembering } & \multirow[t]{2}{*}{ Visual and auditory vividness } & AVR & 20 & 2.70 & 2.06 & \multirow[t]{2}{*}{-0.81} & \multirow[t]{2}{*}{0.21} \\
\hline & & & VR & 22 & 3.18 & 1.79 & & \\
\hline \multirow[t]{2}{*}{$5-2$} & \multirow[t]{2}{*}{ Remembering } & \multirow[t]{2}{*}{ Visual and auditory vividness } & AVR & 20 & 4.25 & 1.83 & -1.12 & 0.14 \\
\hline & & & VR & 22 & 4.77 & 1.07 & & \\
\hline 6 & Applying & Interactivity & AVR & 20 & 2.85 & 0.67 & -0.07 & 0.47 \\
\hline & & & VR & 22 & 2.86 & 0.64 & & \\
\hline 7 & Remembering & Visual and auditory vividness & AVR & 20 & 7.90 & 1.97 & -0.08 & 0.47 \\
\hline & & & VR & 22 & 7.95 & 2.68 & & \\
\hline 8 & Analyzing, evaluating, creating & Interactivity & AVR & 20 & 5.20 & 2.02 & 2.39 & $0.01 *$ \\
\hline & & & VR & 22 & 3.95 & 1.33 & & \\
\hline Total score & & & AVR & 20 & 43.00 & 6.68 & 0.19 & 0.42 \\
\hline & & & VR & 22 & 42.55 & 8.32 & & \\
\hline
\end{tabular}

" $t$ " could not be computed because the standard deviation of both groups was 0

$* p<0.05$ 
Academic achievement through AVR learning was significantly enhanced compared to that through VR learning with regard to the analyzing, evaluating, and creating questions, which had the highest thinking complexity level among all the academic achievement questions.

\subsubsection{Remembering question}

The questions related to remembering involved listening to an explanation given by the captain of the spaceship in the game, and observing the surroundings in the virtual environment, to evaluate the learned contents. There was no special challenge task, and the contents were learned based on the visual and auditory vividness. As there was no difference in visual and auditory vividness, however, between the AVR and VR learning games, it was determined that there was no difference in academic achievement (Table 7).

\subsubsection{Understanding and applying questions}

The questions related to understanding and applying involved learning through challenge tasks and interactions with virtual objects. Theoretically, academic achievement would be higher in AVR than in VR. As shown in Table 7, however, most of the AVR and VR learning game participants gave accurate answers. It was determined that the difficulty level of the challenge task and learning contents was too low, as indicated in Research Hypothesis 1_6, so there was no significant difference in flow. Furthermore, the challenge task was at the level of picking up a stone and dropping it, and observing the results of such action (question 2 ), finding out how far a stone can be thrown on the moon compared to Earth (question 4), and comparing how far the student could jump on the moon and on Earth (question 6). The results of the actions can be easily perceived both in AVR and VR.

What is notable is that in the case of question 6, which compares gravity on Earth and on the moon through the standing long jump, the AVR learning game participants may visually perceive the difference in flight time between jumping on Earth and on the moon while playing the game, but there was no difference in the actual flight time of the body. The actual flight time and the flight time in a virtual space cannot be exactly matched unless special equipment providing motorized interactivity is used to reproduce such special situation. Many students reported that they actually felt like they were jumping away from the moon after the experiment, so it was judged that merely extending the flight time visually made them perceive a difference in gravity.

\subsubsection{Analyzing, evaluating, and creating questions}

As the level of academic achievement in AVR was high with regard to the analyzing, evaluating, and creating questions $(t=2.39, p<.05)$ (Table 7$)$, it can be said that highdimensional thinking skills may be enhanced when AVR is used in learning. The analysis of the academic achievement survey results showed that the AVR learning game participants provided much content related to analyzing, evaluating, and creating in their response to question 8 , which was an analyzing, evaluating, and creating question. Question 8 ("Please describe what you felt when you saw people building stations on the moon drop, or throwing objects") required a detailed explanation of the student's thoughts and feelings based on his own knowledge. The full score was 10 points, and the student was given 0 point if his answer was irrelevant to the question; 3 points if his answer provided a simple feeling or was related to knowledge; 5 points if his answer was related to analyzing, evaluating, or creating based on knowledge; 7 points if his answer was related to any two among analyzing, evaluating, and creating based on knowledge; and 10 points if his answer was related to analyzing, evaluating, and creating based on knowledge.

The analysis of the answers showed that the VR learning game participants provided simple information or feelings, such as "It is astonishing," "The stone fell slowly," and "The stone fell slowly and far away," whereas the AVR learning game participants provided answers that included creative applications by combining analysis and evaluation, such as "I learned that the moon is very different from Earth," "It was astonishing that the stone fell a bit slowly, and I felt a difference in gravity, the stone fell slowly due to the gravity, it is astonishing, and it would be convenient if this were the state of Earth," and "The difference in gravity between Earth and the moon is significant, and thus, various tasks can be performed more easily using this difference."

It can be assumed that this difference occurred due to the effect of experience on the student's thinking. A student who carried out a long jump using AVR answered that "it is astonishing, and I could feel a difference in gravity between Earth and the moon when I long-jumped"; thus, the participant recognized his action as a direct experience, whereas a participant who long-jumped by pressing a button in VR stated that "it was cool, and I wanted to do the same; I also wanted to actually run or throw a stone on the moon". It was as if the student was writing as an observer of a person who long-jumped or threw a stone rather than being the one who did so. It can be said that AVR, which allows an experimental action including an active behavior, is more useful than VR for learning. 


\section{Implications}

The analysis of the results of the survey on the degree of recognizing a virtual experience as a direct experience revealed that the mean value in AVR was generally higher than that in VR, which conformed with the research hypothesis. (That is, the presence, tactile interactivity, and experientiality were significantly enhanced in AVR compared to VR, and the simulator sickness was relieved.) The students felt their experience in AVR more as the actual reality than their experience in VR. In terms of experientiality, AVR is closer to the exploratory stage, referring to the experience of being exposed to an interesting site and directly touching an object there, whereas VR is closer to the spectator stage, referring to an experience that is much like viewing an actual object in a standard environment. Accordingly, more realistic experiential learning is possible in AVR than in VR, and it can be predicted that experiential learning that is closer to reality will become possible in a virtual space with the further development of the relevant technologies.

The analysis of the academic achievement test results in terms of the learning effect showed that there was a partially significant difference in the learning that was obtained from the AVR and VR learning games. With regard to the remembering, understanding, and applying questions, there was no difference in academic achievement between AVR and VR, but the analyzing, evaluating, and creating questions, which required a high thinking complexity level, showed significant academic achievement enhancement in AVR learning. These imply that high-dimensional thinking skills can be enhanced if AVR is used for learning.

\section{Conclusions}

A vivid and highly realistic virtual environment can be achieved by combining a hardware device that can display a virtual object in real time and the already-popularized computer graphics technologies. Three-dimensional technologies enabling a virtual object to be held with the hand and moving inside a virtual space allow people to freely explore a virtual space. Enhancing such vividness and interactivity allows people to feel the virtual experience as an actual experience, allowing reality to be experienced in a virtual space. This study sought to determine whether experiential learning is possible by using virtual experiences. Through experimentation and analysis, it was determined that the enhanced vividness and interactivity in a virtual environment allow the user to recognize the experience as being closer to a direct experience and partially enhance the learning effect. Vividness and interactivity in authentic virtual reality (AVR) are rapidly being enhanced through recent technological developments. It is predicted that learning through an experience identical to reality will be made possible in a virtual space where vividness and the interactivity of all the senses, including the tactile, olfactory, and taste senses, are very close to actual reality. However, the experiments and analysis showed limitations, so the following are suggested for future research:

First, due to the technical restrictions of authentic virtual reality (AVR) and virtual reality (VR) systems that were used in this study, the head-mounted display (HMD) and the system unit were connected using a cable, but it appears that this design problem interfered with the accurate measurement of the locomotive interactivity and flow in AVR. Accordingly, it will be necessary to measure and analyze these elements after removing the cable, which restricts free movement.

Second, experiments were conducted via VIVE in this study, considering the age restriction condition and freedom of contents and operation. Therefore, the experiential learning potential of the VR systems providing tactile interactivity using gloves, locomotive interactivity using treadmills, and motorized interactivity could not be verified. Future studies should explore the possibilities of experiential learning in VR, which provides these types of interaction, by performing additional experiments.

Third, to remain within the framework of the curriculum, this study made use of learning contents and a challenge task that were too easy in terms of AVR. As such, a result contrary to the hypothesis was obtained in terms of flow, and there were restrictions that partially enhanced the learning effect in terms of academic achievement. Accordingly, the evaluation results should be supplemented by experimenting on and realizing contents for the high-level grades, which have a high level of difficulty, based on the analysis results indicating that AVR is suitable for difficult and complex learning and challenge tasks.

Fourth, this study showed that experiential learning is possible in a virtual space, and it was thus deduced that experiential learning using a virtual environment is also possible. Even if experiential learning is possible in theory, however, it will not be easy to immediately apply this system at this stage, where only one student can participate in the activities in one system. Accordingly, technical studies must be conducted and contents must be developed to enable many students to participate in learning at the same time.

Fifth, the characteristics of VR deduced through theoretical analysis (presence and flow), and the factors that contribute to presence (vividness, tactile interactivity, locomotive interactivity, and simulator sickness) and learning effect can set an overall influential relationship, as shown in Fig. 8. Accordingly, the theoretical model must be set and verified, as shown in Fig. 8. To validate the suitability of a theoretical model with such a complicated relationship, structural equation modeling (SEM) analysis is generally conducted to assess the fit of the 
Fig. 8 Influence relations among vividness, tactile interactivity, locomotive interactivity, simulator sickness, presence, flow, and learning effect

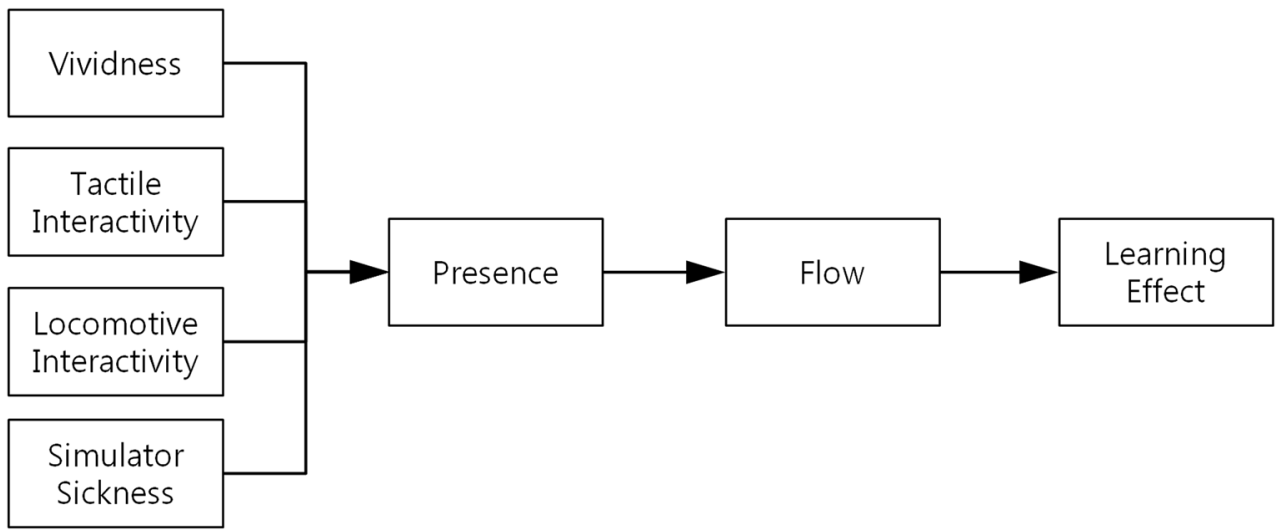

latent variable model based on theoretical structural modeling. The sample size in this regard must be 5-10 times more than the number of parameters, and there must be more than 150 people involved (Kim et al. 2009). In the AVR and VR systems that were used in this study, however, an HMD had to be worn for learning, making it impossible for multiple students to participate in the said systems simultaneously. Also, due to the various restrictions, such as the need to conduct an experiment in accordance with the class schedule and to put the students under control before and after the experiment, a sufficient number of samples could not be secured for the SEM analysis. Accordingly, the influential relationship among the characteristics of VR, the components that contribute to these characteristics, and the learning effect must be examined in the future studies by verifying the theoretical model after securing a sufficient number of samples.

Open Access This article is distributed under the terms of the Creative Commons Attribution 4.0 International License (http://creativeco mmons.org/licenses/by/4.0/), which permits unrestricted use, distribution, and reproduction in any medium, provided you give appropriate credit to the original author(s) and the source, provide a link to the Creative Commons license, and indicate if changes were made.

\section{References}

Anderson LW, Krathwohl DR, Airasian PW, Cruikshank KA, Mayer RE, Pintrich PR, Raths J, Wittrock MC (2001) A taxonomy for learning, teaching, and assessing: a revision of Bloom's taxonomy of educational objectives, Complete edn. Longman, New York

Bailenson JN, Yee N, Blascovich J, Beall AC, Lundblad N, Jin M (2008) The use of immersive virtual reality in the learning sciences: digital transformations of teachers, students, and social context. J Learn Sci 17(1):102-141. https://doi. org/10.1080/10508400701793141

Barfield W, Hendrix C (1995) The effect of update rate on the sense of presence within virtual environments. Virtual Real 1(1):3-15. https://doi.org/10.1007/BF02009709

Blake J, Gurocak HB (2009) Haptic glove with MR brakes for virtual reality. IEEE/ASME Trans Mechatron 14(5):606-615
Böcker M, Mühlbach L (1993) Communicative presence in videocommunications. In: Proceedings of the human factors and ergonomics society annual meeting, SAGE Publications 37(3), pp 249-253

Bouzit M, Burdea G, Popescu G, Boian R (2002) The Rutgers Master II-new design force-feedback glove. IEEE/ASME Trans Mechatron 7(2):256-263

Bracken CC, Skalski P (2010) Immersed in media: telepresence in everyday life. Routledge, London

Brennan D (2017) Holovis uses giant robot arms for intense VR motion simulated experiences. Road to VR. https://www.roadt ovr.com/holovis-uses-giant-robot-arms-intense-vr-motion-simul ated-experiences/. Accessed 15 Jan 2018

Burdea G, Popescu V, Hentz V, Colbert K (2000) Virtual realitybased orthopedic telerehabilitation. IEEE Trans Rehabil Eng 8(3):430-432

Cakmak T, Hager H (2014) Cyberith virtualizer: a locomotion device for virtual reality. In: ACM SIGGRAPH 2014 emerging technologies ACM, 6

Chance SS, Gaunet F, Beall AC, Loomis JM (1998) Locomotion mode affects the updating of objects encountered during travel: the contribution of vestibular and proprioceptive inputs to path integration. Presence 7(2):168-178

Connelly L, Jia Y, Toro ML, Stoykov ME, Kenyon RV, Kamper DG (2010) A pneumatic glove and immersive virtual reality environment for hand rehabilitative training after stroke. IEEE Trans Neural Syst Rehabil Eng 18(5):551-559

Csikszentmihalyi M (1990) Flow: the psychology of optimal experience. HarperPerennial, New York

Csikszentmihalyi M (2000) Beyond boredom and anxiety, second printing. Jossey-Bass, San Francisco

Csikszentmihalyi M, Larson R (1986) Being adolescent: conflict and growth in the teenage years. Basic Books, New York

Csikszentmihalyi M, Rathunde K, Whalen S (1997) Talented teenagers: the roots of success and failure. Cambridge University Press, Cambridge

Darken RP, Cockayne WR, Carmein D (1997) The omni-directional treadmill: a locomotion device for virtual worlds. In: Proceedings of the 10th annual ACM symposium on user interface software and technology ACM, pp 213-221

De Souza e Silva A, Delacruz GA (2006) Hybrid reality games reframed: potential uses in educational contexts. Games Cult $1(3): 231-251$

Dewey J (1959) The child and the curriculum, vol 5. University of Chicago Press, Chicago

Dewey J (2004) Democracy and education. Courier Corporation, North Chelmsford 
Draper MH, Viirre ES, Furness TA, Gawron VJ (2001) Effects of image scale and system time delay on simulator sickness within head-coupled virtual environments. Hum Factors J Hum Factors Ergon Soc 43(1):129-146

Dunleavy M (2014) Design principles for augmented reality learning. TechTrends 58(1):28-34

Elias GS, Garfield R, Gutschera KR (2012) Characteristics of games. MIT Press, Cambridge

EyeSight Mobile Technologies Ltd. (2016) EyeSight gesture control for smartphone-Powered VR. https://www.youtube.com/chann el/UCLU18k-KJTs_B6CJa3ICTFQ. Accessed 15 Jan 2018

Foxlin E, Harrington M, Pfeifer G (1998) Constellation: a widerange wireless motion-tracking system for augmented reality and virtual set applications. In: Proceedings of the 25th annual conference on Computer graphics and interactive techniques ACM, pp 371-378

Gibbons M, Hopkins D (1980) How experiential is your experiencebased program? J Exp Edu 3(1):32-37

Heeter C (1992) Being there: the subjective experience of presence. Presence: Teleop Virtual Environ 1(2):262-271

Hoffman DL, Novak TP (1996) Marketing in hypermedia computer-mediated environments: conceptual foundations. J Mark 60:50-68

Hou J, Nam Y, Peng W, Lee KM (2012) Effects of screen size, viewing angle, and players' immersion tendencies on game experience. Comput Hum Behav 28(2):617-623

Iwata H, Fujii T (1996) Virtual perambulator: a novel interface device for locomotion in virtual environment. In: Proceedings of the 1996 virtual reality annual international symposium, pp 60-65

Iwata H, Yoshida Y (1999) Path reproduction tests using a torus treadmill. Presence Teleop Virtual Environ 8(6):587-597

Izard SG, Mendez JAJ, Palomera PR (2017) Virtual reality educational tool for human anatomy. J Med Syst 41(5):76

Jackson SA, Marsh HW (1996) Development and validation of a scale to measure optimal experience: the flow state scale. J Sport Exerc Psychol 18(1):17-35

Kamarainen AM, Metcalf S, Grotzer T, Browne A, Mazzuca D, Tutwiler MS, Dede C (2013) EcoMOBILE: integrating augmented reality and probeware with environmental education field trips. Comput Edu 68:545-556

Kennedy RS, Lane NE, Berbaum KS, Lilienthal MG (1993) Simulator sickness questionnaire: an enhanced method for quantifying simulator sickness. Int J Aviat Psychol 3(3):203-220

Kim JH, Kim MG, Hong SH (2009) Writing a paper as a structural equation model. Communication Books, Seoul

Klopfer E, Sheldon J (2010) Augmenting your own reality: student authoring of science-based augmented reality games. New Dir Youth Dev 128(Winter):85-94

Klopfer E, Squire K, Jenkins H (2002) Environmental detectives: PDAs as a window into a virtual simulated world. In: Proceedings of the IEEE international workshop on wireless and mobile technologies in education, pp 95-98

Kolb DA (1984) Experiential learning: experience as the source of learning and development. Prentice-Hall, Englewood Cliffs

Kwon C, Kim Y, Woo T (2016) Digital-physical reality game: mapping of physical space with fantasy in context-based learning games. Games Cult 11(4):390-421

Lang B (2016) Hands-on: oculus Touch 2016 prototype brings refinements to an already elegant design. Road to VR. http://www.roadt ovr.com/hands-on-oculus-touch-2016-prototype-brings-refin ements-to-an-already-elegant-design/. Accessed 15 Jan 2018

Lave J, Wenger E (1991) Situated learning: legitimate peripheral participation. Cambridge University Press, Cambridge

Lombard M, Ditton TB (1997) At the heart of it all: the concept of presence. J Comput Mediated Commun. https://doi. org/10.1111/j.1083-6101.1997.tb00072.x
Maraj CS, Badillo-Urquiola KA, Martinez SG, Stevens JA, Maxwell DB (2017) Exploring the impact of simulator sickness on the virtual world experience. In: Kantola JI, Barath T, Nazir S, Andre T (eds) Advances in human factors, business management, training and education. Springer, Cham, pp 635-643

Massimini F, Carli M (1988) The systematic assessment of flow in daily experience. In: Csikszentmihalyi M, Csikszentmihalyi IS (eds) Optimal experience: psychological studies of flow in consciousness. Cambridge University Press, Cambridge, pp 266-287

Mentira (2009). Mentira. http://www.mentira.org/. Accessed 15 Jan 2018

Microsoft Inc. (2014) Handpose: fully articulated hand tracking. https://www.microsoft.com/en-us/research/search/?q=Handp ose $\% 3 \mathrm{~A}+$ Fully+Articulated+Hand+Tracking. Accessed 15 Jan 2018

Munnerley D, Bacon M, Wilson A, Steele J, Hedberg J, Fitzgerald R (2012) Confronting an augmented reality. In: ALT-C 2012 conference proceedings, pp 39-48

Neuman WR (1990) Beyond HDTV: exploring subjective responses to very high definition television. Media Laboratory, Massachusetts Institute of Technology

Nichols S, Haldane C, Wilson JR (2000) Measurement of presence and its consequences in virtual environments. Int J Hum Comput Stud 52(3):471-491

Novak TP, Hoffman DL, Yung YF (2000) Measuring the customer experience in online environments: a structural modeling approach. Mark Sci 19(1):22-42

Oculus (2018) https://www.oculus.com/. Accessed 15 Jan 2018

Perry B (2014) Gamifying French language learning: a case study examining a quest-based, augmented reality mobile learning-tool. Proced Soc Behav Sci 174:2308-2315

PilotBit Inc. (2018) Full hand skeleton tracking. PilotBit. http://www. pilotbit.com/. Accessed 15 Jan 2018

Prensky M (1998) Twitch speed: keeping up with young workers. Across the Board

Priest S, Gass MA (2005) Effective leadership in adventure programming. Human Kinetics, Champaign

Reeves B, Detenber B, Steuer J (1993) New television: the effects of big pictures and big sound on viewer responses to the screen. In: Paper presented to the Information Systems Division of the International Communication Association

Robertson A (2015) Valve's virtual reality headset is great, but its controllers are the real story. The Verge. http://www.theverge. com/2015/3/4/8150653/valve-steam-controller-vive-vr-gdc-2015. Accessed 15 Jan 2018

Salen K, Zimmerman E (2004) Rules of play: game design fundamentals. MIT press, Cambridge

Schubert TW (2003) The sense of presence in virtual environments: a three-component scale measuring spatial presence, involvement, and realness. Zeitschrift für Medienpsychologie 15(2):69-71

Schubert TW, Friedmann F, Regenbrecht HT (1999) Decomposing the sense of presence: Factor analytic insights. In 2nd International workshop on presence

Schubert TW, Friedmann F, Regenbrecht HT (2001) The experience of presence: factor analytic insights. Presence Teleop Virtual Environ 10(3):266-281

Seibert J, Shafer DM (2017) Control mapping in virtual reality: effects on spatial presence and controller naturalness. Virtual Reality 22:1-10

Shafer DM, Carbonara CP, Popova L (2011) Spatial presence and perceived reality as predictors of motion-based video game enjoyment. Presence: Teleop Virtual Environ 20(6):591-619

Sheridan TB (1992) Musings on telepresence and virtual presence. Presence: Teleop Virtual Environ 1(1):120-126

Shin J, An G, Park JS, Baek SJ, Lee K (2016) Application of precise indoor position tracking to immersive virtual 
reality with translational movement support. Multimed Tools Appl 75(20):12331-12350

Sixense (2018) https://www.sixense.com/. Accessed 15 Jan 2018

Skalski P, Tamborini R, Shelton A, Buncher M, Lindmark P (2011) Mapping the road to fun: natural video game controllers, presence, and game enjoyment. New Med Soc 13(2):224-242

Slater M, Usoh M (1993) Representations systems, perceptual position, and presence in immersive virtual environments. Presence Teleop Virtual Environ 2(3):221-233

Squire K, Jan M (2007) Mad city mystery: developing scientific argumentation skills with a place-based augmented reality game on handheld computers. J Sci Edu Technol 16(1):5-29

Squire K, Klopfer E (2007) Augmented reality simulations on handheld computers. J Learn Sci 16:371-413

Steuer J (1993) Defining virtual reality: dimensions determining telepresence. J Commun 42(4):73-93

Suma EA, Babu S, Hodges LF (2007) Comparison of travel techniques in a complex, multi-level $3 \mathrm{~d}$ environment. In: IEEE symposium on 3D user interfaces, 2007. 3DUI'07. IEEE, pp 149-155

Tactical Haptics (2018) http://tacticalhaptics.com/. Accessed 15 Jan 2018

Treleaven J, Battershill J, Cole D, Fadelli C, Freestone S, Lang K, Sarig-Bahat H (2015) Simulator sickness incidence and susceptibility during neck motion-controlled virtual reality tasks. Virtual Real 19(3-4):267-275
Villard C, Soler L, Gangi A (2005) Radiofrequency ablation of hepatic tumors: simulation, planning, and contribution of virtual reality and haptics. Comput Methods Biomech Biomed Eng 8(4):215-227

Virtuix Omni (2018) http://www.virtuix.com/. Accessed 15 Jan 2018

VIVE (2018) https://www.vive.com/. Accessed 15 Jan 2018

Witmer BG, Singer MJ (1998) Measuring presence in virtual environments: a presence questionnaire. Presence: Teleop Virtual Environ 7(3):225-240

Yuyama I (1982) Fundamental requirements for high-definition television systems: large screen effects. HNK Tech Monogr 32:14-20

Zaman M, Anandarajan M, Dai Q (2010) Experiencing flow with instant messaging and its facilitating role on creative behaviors. Comput Hum Behav 26(5):1009-1018

Zanbaka CA, Lok BC, Babu SV, Ulinski AC, Hodges LF (2005) Comparison of path visualizations and cognitive measures relative to travel technique in a virtual environment. IEEE Trans Vis Comput Graph 11(6):694-705

Zeltzer D (1992) Autonomy, interaction, and presence. Presence Teleop Virtual Environ 1(1):127-132

Zyda M (2005) From visual simulation to virtual reality to games. Computer 38(9):25-32 